\title{
Água de moinho: práticas transformadoras em arte e pesquisa, modos de estar com o outro em trocas intensas, de ser fluxo
}

\author{
Watermill: transformative practices in art and \\ research, ways of being with each other in intense \\ exchanges, to be flow
}

Fátima Branquinho (Faculdade de Educação e do Programa de Pós Graduação em Meio Ambiente da UERJ)

Fátima Kzam (Instituto de Química da UERJ) Isabela Frade(Instituto de Artes da UERJ) Daniele Alves (PPGARTES/UERJ)

\begin{abstract}
RESUMO: Esse artigo indica a possibilidade de realizarmos experiências transformadoras de educação ambiental, ciência e arte na formação de educadores e pesquisadores a partir da produção de conhecimento sobre a realidade. Trata-se de contribuir para pensarmos uma complexa rede que se estabelece em nossos espaços-lugares de ação educativa entre atores estado, academia, indústria, instituições não governamentais, comunidades, lideranças locais e os sujeitos coletivos - que produzem simultaneamente a vida e o conhecimento sobre a vida. A compreensão dessa trama implica experiências alternadas de realização de atividades nas comunidades da região carioca entre Universidade do Estado do Rio de Janeiro (UERJ)e Mangueira. Misturando comunidade e universidade experienciamos um movimento de desierarquização do conhecimento e a conjunção das sensibilidades.
\end{abstract}

Palavras chave: arte, ciência, vida, educação, hierarquia de saberes.

\section{Abstract:}

This article has the purpose to show the possibilities of some transformative experiences on environmental education by the subject of science and art aming the formation of educators and researchers. Trought critical reflection on the production of knowledge directly over reality, it contributes to reinforce the thought over the complex network that is developed in our educational activity spaces-places among different actors - state, academia, industry, non-governmental institutions, communities, local leaders and the collective subjects - simultaneously productors of life and its knowledge. Understanding this web involves alternating 


\section{(7) Revrsta \\ 4) APOTHEKE}

experiences on conducting activities in between diferent cultural spaces as UERJ and Mangueira community, in Rio de Janeiro, Brasil. Mixing university and community, we experience non-hierarchized knowledge and sensibilities conjunction.

keywords: art, cience, life, education, knowledge hierarchy.

\section{I - Arte e vida}

Chegamos ao Jardim pelo correr das coisas mesmo, simplesmente por seguir, adiante, sentindo o repuxo do mundo. As coisas a que nos referimos são processos vividos em um território conquistado pouco a pouco. Uma obra em ação conjunta por muitas pessoas, um enlace de corpos em progressivo adensamento. A natureza nos advém pela sua neutralidade própria combinada à sua complexidade semântica. Num campo verde que serve de terceiro termo (DERRIDA, 2001) para que uma conjunção social se dê. Um espaço de vida. Animação social buscando espaço para acontecer. Arte de "nãoartistas", ou "arte comum", de todos, arte/vida se fazendo necessária: ferramenta para o existir em diálogo mais profundo com o mundo natural e social, um entrecruzar de sensibilidades múltiplas em formas livres.

Em um momento onde o risco de vida é iminente (DANOWSKI e VIVEIROS DE CASTRO, 2015), emocionados pelos desastres ambientais "sem volta", no envenenamento das fontes, da contaminação dos solos, da proliferação do lixo, das chuvas ácidas e do esgarçamentos das teias bioenergéticas, dos subsequentes desencontros dos povos e comunidades, das sucessivas crises econômicas; nos dispomos a produzir um campo de abrigo a uma consciência pedagógica coletivizante que nasce pelas inteligências e sensibilidades em troca.

Há que se reparar que os nossos espaços se revertem, se misturam, se inventam. Chamamos, em arte, de escultura social esse trabalho de gerar novas formas de organização; não se privilegia, assim, as questões visuais, mas formas relacionais, potenciais dispositivos amplificadores que atuam 


\section{《)}

como disparadores de novas conformações sociopolíticas: é essa nossa aventura no Jardim. Trata-se de abrir espaço para se estar junto, gerando novos campos relacionais (FRADE, 2012). Começamos em um monturo de lixo. Aconteceu de nos parecer assim como condição de servir para a produção de um lugar vazio, pleno de possibilidades. Uma motivação a estar em companhia na produção desse espaço-tempo de liberdade.

o Jardim nos trouxe uma condição rica de desdobramentos, de novas possibilidades e nos revelou novas dimensões na arte. Trouxe ainda o impulso para a reunião de outras áreas nesse experimento. Requisitou, para tanto, a ciência ambiental que se torna parceira desta empreitada acadêmica que se alia à biologia relacional complexa (MATURANA e VERDEN-ZOLLER, 2009), à antropologia da ciência (LATOUR, 2012) e das mobilidades (AUGÉ, 2014), à geografia social (YU-FU TAN, 2005), que vem se aliando à filosofia contemporânea da arte (GROYS, 2008, DIDIHUBERMAN 2014) e à teoria crítica da cultura (BOAVENTURA DOS SANTOS, 2006) e tantos outros pensamentos e teorias que fecundam esse pensamento sobre o jardim. Este mesmo um objeto (objeto/espaço) de arte que poderá a ser fecundo para as teorias transdisciplinares. Neste sentido, uma grande surpresa veio se somar às esperadas relações conceituais, com a História da Arte (CAUQUELIN, 2007): o surpreendente encontro da teoria da desconstrução com a experiência da produção de um jardim, como foi o caso da (não)criação do Jardim e todo o pensamento da arquitetura que segue seu próprio deslocamento e vai pensar nas praças, nas ruas como "zonas de espera e encontro" (FŨ̃O, 2014, DOURADO, 2011), e nossas próprias trajetórias sobre o feminismo e a arte da terra (FRADE, 2010) que se produzem em tramas conceituais por onde se pratica a pesquisa-ação Jardim da Tia Neuma[1], na Mangueira.

Joseph Beuys em seu tratado sobre as plantas nos lança para mais além, trazendo ainda os aspectos espirituais de uma 


\section{X|}

ação transformadora. Há uma alquimia profunda nesta investida, no que o artista identificava como um necessário processo de cura: a aproximação entre arte e vida. A planta, em seu processo de síntese da luz, e sua estrutura replicante, representa uma forma coletiva de relação proveitosa para cada indivíduo da espécie: "O importante aqui, não é a figura individual, mas o conjunto, o órgão que pode se desenvolver quando os indivíduos se contêm em benefício do todo." (HARLAN, $2010, \mathrm{p} .31$ )

Os processos vitais estão conectados com essa trama infinita e delicadamente produzida pelo complexo energético que denominamos natureza. Mergulhar nessas teias é encarar as mais complexas articulações e aceitar nosso parcial entendimento, ou, como nos diz Latour (Op. Cit.), nossas certezas provisórias. Por isso o trabalho coletivo, por isso o aporte colaborativo, por isso o abandono das fronteiras e das hierarquias. Todo saber tem lugar neste processo. Também no Jardim do Nêgo, em Nova Friburgo, na serra fluminense, aonde o artista esculpe o barro transformando-o em gente, em animais, em música, em literatura, em vida. O Nêgo (Geraldo Simplício) se alimenta do jardim que cultiva, neste ofício de escultor jardineiro, cultivador de musgos e líquens. As esculturas vivas na terra são sua energia, sua respiração. Um misto de educador ambiental, arquiteto, engenheiro, plantador, escultor, Nêgo mistura encantamento, técnica, inspiração, sonho, literatura e mitologia sem nunca ter frequentado os bancos escolares. (CONDURU, 1998) 


\section{V)}

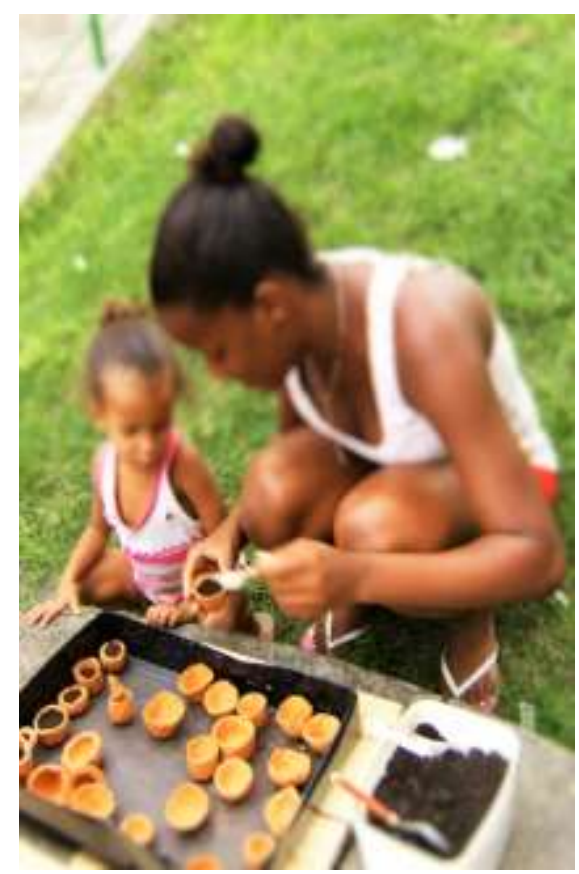

Imagem 01: mãe e filha juntas produzem mudas nos pequenos recipientes produzidos pelas crianças da Creche Nação Mangueirense

A produção do Jardim envolve o reconhecimento de saberes da própria comunidade e inquire as competências do pesquisador: a hierarquia dos saberes muitas vezes se encontrou invertida e estamos aprendendo a "jardinar". Aqui destacamos o aporte intergeracional apresentado acima, na imagem 1: mãe e filha juntas produzem mudas nos pequenos recipientes produzidos pelas crianças da Creche Nação Mangueirense.

\section{II - Sobre a arte dos jardins e suas histórias:}

Permeando a história do homem, temos a forte presença de todo tipo de jardim, sendo este uma das primeiras formas de expressão na sua relação com a natureza. O termo jardim é amplo e absorve vários conceitos de acordo com o seu entendimento e criação em cada cultura. Na antiguidade, geralmente estava relacionado à beleza, ao divino, à sedução e à fecundidade. Podemos retomar o Jardim do Éden, citado na Bíblia: conforme passagem dessa escritura, Deus planta um 


\section{X|}

jardim e o confia-o nas mãos do homem para que possa cuidar e guardar. Neste caso, o homem é representado por Adão e Eva e o Jardim do Éden como a referência imagética do paraíso. Neste mesmo sentido mítico do paraíso temos os jardins Ida-Varsha dos hindus, os bosques sagrados dos itálicos e os Eridus dos assírios. Os jardins suspensos da Babilônia são considerados os mais antigos, datando de 604 - 562 a.C. Jardins eram, também, comumente ofertados aos deuses na Mesopotâmia. Temos os jardins presentes em muitas civilizações, como o Jardim Egípcio, Persa, Grego, Romano, Islâmico, Renascentista, Barroco, o romântico Inglês e já no século XV surgem os hortos botânicos (ALVES, ROCHA, 2014).

No século XVIII observa-se a prática do restauro de alguns jardins antigos (BERJMAN, 2011) e, à medida que as cidades foram se expandindo, surgiram os jardins privados e as praças e passeios públicos dos séculos XIX e XX. Nesta trajetória, vários documentos foram lançados em defesa da proteção e conservação de áreas verdes, como exemplo, a Declaração Internacional de Direitos à Memória da Terra, de 1991, e a Carta de Bagé, de 2007, denominada Carta da Paisagem Cultural, a qual abordou, de maneira pioneira, a relação do homem com a natureza aplicada à realidade nacional[4]. Segundo seu Artigo 2, paisagem cultural:

é o meio natural ao qual o ser humano imprimiu as marcas de suas ações e formas de expressão, resultando em uma soma de todas os testemunhos resultantes da interação do homem com a natureza e, reciprocamente, da natureza com homem, passíveis de leituras espaciais e temporais. (CARTA DE BAGÉ, 2007)

Além da Declaração de Foz do Iguaçu, também conhecida como Carta do Espírito dos Lugares, lançada em 2008 pelo ICOMOS, e a Carta Colombiana da Paisagem, lançada em 2010 pela Sociedade Colombiana de Arquitetos Paisagistas, no mesmo ano a Associação Brasileira de Arquitetos Paisagistas publica a Carta Brasileira da Paisagem: 


\section{X|}

Reestruturação de paisagens urbanas degradadas de modo integrado, como propulsores de novas dinâmicas: urbanas, sociais, culturais, biofísicas e econômicas, e de melhoria do quadro de vida da população. (CARTA BRASILEIRA DA PAISAGEM, 2010)

Neste longo caminho, os diferentes jardins, cada um com suas peculiaridades, das mais diversas culturas, entraram para a história, sendo considerados grandes monumentos ligados, geralmente, às moradias importantes ou a fatos históricos memoráveis. Um passo importante para o desenvolvimento deste campo foi, segundo Berjman (Op. cit.), a confluência de disciplinas como a antropologia, a geografia e o urbanismo, as quais, no decorrer do século XIX, passaram a perceber a paisagem com um conceito holístico, considerando as relações da natureza com o homem e suas implicações sociais.

Após algumas questões sobre o universo temático dos jardins e pelo caminho de crescente inserção e valorização de determinadas áreas verdes enquanto patrimônio, focamos agora nas possibilidades de abordagem e nos instrumentos disponíveis para a criação de jardins comunitários, prática crescente em nossas cidades do Século XXI, seja aqui no Brasil ou em outra metrópole do exterior. Podemos dizer que o reconhecimento da questão dos jardins como espaço lúdico está diretamente ligado ao fato de serem percebidos de forma integral. Sua essência na natureza passa a estar conectada também ao universo da identidade do território que ocupa, agregando, assim, a questão histórico-cultural que sua preservação necessita. Como tudo na natureza, os jardins possuem um intenso ciclo de renovação e deterioração. Porém, no caso dos jardins comunitários, a intenção passa a ser preservar o espaço de uma determinada forma contínua na inter-relação entre vizinhos e visitantes. Por isso, o desafio dos jardins comunitários que exigem medidas comprometidas de todos com sua manutenção, 


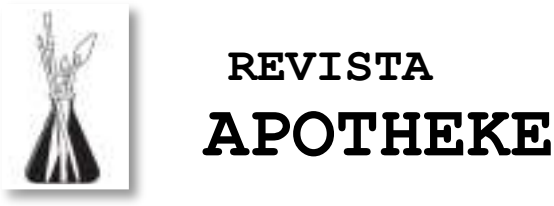

planejamento e manejo. Há também uma nova história surgindo aqui.

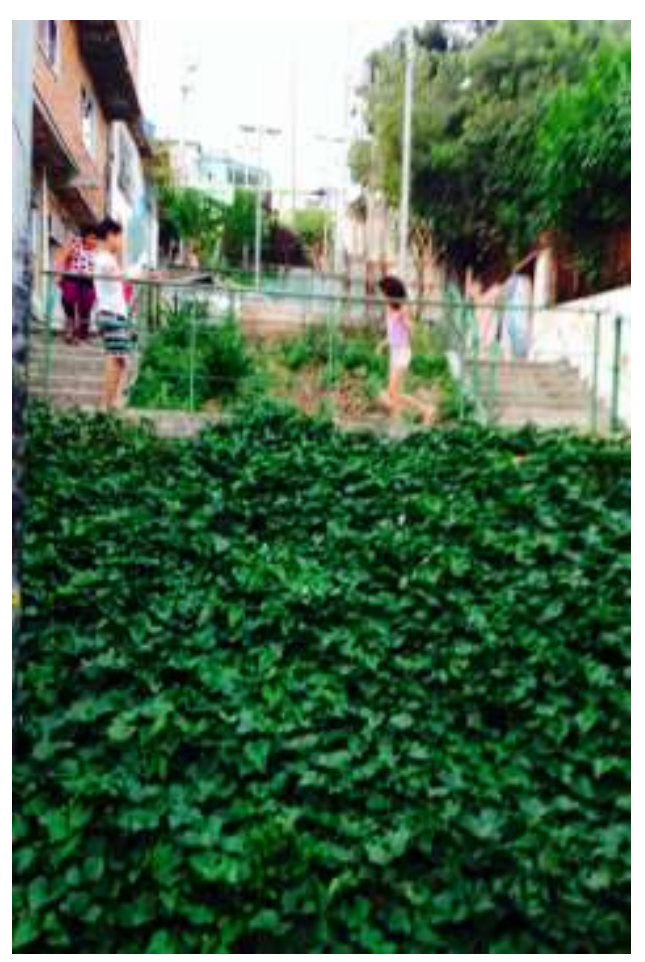

Imagem 2

Uma bela experiência botânica pode ser evocada no jogo infantil (Imagem 2): - Que é mais doce que o pé de batata doce? O pé de batata doce plantado por moradores na Rua Icaraí se espalhava em ondas verdes, inundando todo o platô e continha outra experiência doce: O jogo de amarelinha começou a fazer parte das brincadeiras diárias e, nesta escadaria, uma pequena praça começou a ressurgir. Como último plano nesta paisagem de afetos, pés de feijão, milho, capim limão, couve e chuchu se sucederam na conformação de um campo de experiências comuns.

III - Vida de pesquisador:

sistematizando uma contribuição científica na formação de educadores 


\section{R| Revrsta \\ A APOTHEKE}

O que sustenta a realização das práticas transformadoras as quais nos referimos? São seis as noções-chave que consideramos, nos ajudam a pensar como fazer pesquisa, como construir conhecimento sobre a realidade e, especialmente, como agir no sentido de realizar práticas transformadoras. No trabalho em desenvolvimento, a ficção da arte e a verificação científica são ambas válidas. A imaginação e a realidade se mesclam, implicam-se mutuamente. Qualquer experiência é absorvida nestes dois sentidos, como ciência e como arte, entendida como dois lados da vida, sendo estes um só. Nesse sentido, ambas, ciência e arte, comprometem-se no envolvimento com a comunidade de moradores da Rua Icaraí, na Zona Buraco Quente, na Mangueira, Rio de Janeiro. Um pequeno jardim, como projeto coletivo, é ensejado envolvendo a Creche Municipal Nação Mangueirense. Na entrada da escola, o espaço "entre", estabelecido como lugar mediador entre escola, comunidade e universidade.

A primeira noção-chave, já mencionada, é a desierarquização de saberes, onde vale a palavra de todos. A pesquisa e a prática relacional a ela atrelada - são traduções do desconforto interno do que queremos ver transformado: a supremacia de algum tipo de saber sobre outro. O que fazer de tanta sabedoria e conhecimento daqueles com quem trabalhamos os participantes dos projetos, os sujeitos (humanos e não humanos) e sua presença filtrada pelos relatos dos pesquisadores - e que não estão contemplados na academia? Como é possível ignorar seu modo de lidar com a natureza, de cuidar da saúde, de explicar o céu, a terra, o mar? Como, abandonando algum modismo pedagógico, poderíamos considerar a noção segundo a qual educar é partir do conhecimento já vivido para elevar esse patamar de conhecimento sobre a realidade até o conhecimento científico? Acreditamos que há nexos, conexões, pontes, elementos de travessia que possibilitam contato entre 


\section{(A) APOTHEKE}

universos cognitivos; promover diálogos entre saberes tradicionais/populares e saberes científicos nos permite afirmar que vivemos em um mesmo mundo comum.

o que de um conjunto de conhecimentos ressoa no outro? Há uma circularidade, como não reconhecer?! (BRANQUINHO, 2007) Mas, para além deste reconhecimento e da importância que o conhecimento tradicional tem para alguns setores e espaços da vida de todos - vida acadêmica ou não - ainda é preciso colaborar para a admissão dessa circularidade e importância desse conhecimento não científico na academia. Afinal, quais noções podem ser reunidas, no fazer da pesquisa e da docência em arte e em ciência, para fortalecer o argumento definitivo sobre o fato das diferenças que existem entre saberes, por si só, não justificarem hierarquização?

Esse argumento precisa ser forte, ser sólido e precisa falar a linguagem da ciência, passando por dentro dela, utilizando seus próprios elementos e sua lógica. Quando LeviStrauss (1989) escreve "O pensamento selvagem" afirma que mesmo os grupos que não tem a ciência como instrumento de leitura do mundo, tal como a conhecemos hoje, possuem um conhecimento que tem valor: a ciência do concreto. Afinal, para Levi-Strauss (Op. Cit), o processo de classificar está na base de todo pensamento. Mas, algo de "selvagem" ainda estava presente, assim, ainda não nos sentimos convencidos. Quando Latour (1994) publica "Jamais fomos modernos: ensaio de antropologia simétrica", algo ressoa um pouco mais definitivo para a reunião de algumas noções que nos ajudam a construir o argumento da desierarquização entre saberes, tão cara para os diálogos entre a ciência e a arte. Tais noções, ao mesmo tempo, estranhas e familiares podem ajudar na compreensão do mundo comum a todos nós, que parece partido, pouco inteligível quando se trata de olhar para redes de saberes que trançam visão de mundo e modos de vida e trabalho. Com elas, passamos 


\section{¿|}

a operar no universo das plantas e dos saberes que nelas se investem. Com as ferramentas desse referencial teórico, onde se destaca Latour (Op. Cit), a teoria ator-rede, que se desdobra sobre o conhecimento em termos completamente práticos.

Uma segunda noção que nos convoca a ser pensada é a noção de tempo. Assim como encontramos na negação do moderno (LATOUR, Op. Cit). Um grupo de dança e canto de Capivari, Vale do Jequitinhonha, é exemplo vivo disso, quando, em uma apresentação, a dirigente informa o nome do grupo e o explica:

Quatro gerações, não porque existimos há quatro gerações... nem sei há quantas gerações fazemos esse trabalho! Quatro gerações, porque temos sempre no palco crianças, jovens, adultos e idosos cantando e dançando a nossa arte!

Assim se produzem as esculturas na terra já mencionadas no Jardim do Nêgo, aonde, nas palavras de Conduru (Op. Cit., $\mathrm{s} / \mathrm{p})$,

no imaginário dominado pelo artista, confluem diversos tempos e culturas, estando presentes desde temas sacros (o presépio) até motivos profanos (a nega fulô), desde problemas contemporâneos e locais (os retirantes) até questões ancestrais e universais (a mulher e a serpente, entre outros seres e animais).

Essa mesma ideia está no Almanaque Toda Oficina da Vida, escrito por Nogueira (2008), quando ela nos diz que nem sempre se registrou o tempo como hoje, e complementa Latour (Op. Cit., p. 32):

Tal fato reitera a universalidade da condição humana que busca grandes referências - recortes de tempo - que possam integrar diversos grupos sociais em um movimento de aproximação que, simultaneamente, resguarde as marcas de suas especificidades...

Os saberes sobre as plantas medicinais (BRANQUINHO, 2007) também revela a possibilidade de assumir a mesma postura diante do tempo quando buscamos o que ressoa da fala de uma erveira na fala de uma pesquisadora do campo da botânica. Quando perguntada sobre como ela sabe se uma planta é medicinal, a erveira afirma: "Todas elas curam algo... se não prestamos atenção nelas, não sabemos para que serve"... E, a pesquisadora diz: "nossa tecnologia ainda não nos permitiu identificar para que serve seu principio ativo, mas toda 


\section{(A) APOTHEKE}

planta é medicinal em si mesma, nós é que ainda não sabemos". No ensaio sobre a ciência das qualidades, Capra (2011, p.43) destaca uma expressão explicita dessa visão sobre o que é conhecer, presente em Leonardo Da Vinci:

As virtudes das ervas, das pedras e das plantas não existem porque os homens não as tenham conhecido (...). Mas, diremos que essas ervas permanecem nobres em si mesmas sem a ajuda das línguas e das letras humanas.

A postura epistemológica que rejeita a noção de tempo como seta irreversível - progresso ou decadência - tem uma consequência sobre a pesquisa, sobre o ato de pesquisar. Stengers (2013), no livro "Uma outra ciência é possível", sugere uma reflexão sobre o tempo da pesquisa, traz a noção de uma desaceleração da ciência, pede para irmos mais devagar, um mais devagar teórico, tal e qual nos lembra Nogueira (op. Cit.), na obra já citada, sobre a postura do sertanejo - que combina real e imaginário, razão e desrazão, natureza e cultura, em um exercício estranho e contundente de conexão de saberes e interdependência de noções. Seus estudos indicam que é preciso observar mais, perceber mais, hesitar mais ao construirmos um conhecimento sobre a realidade que nos interessa compreender. Essa terceira noção - de desaceleração - não é, assim, apenas temporal. Isso significa dizer que os grupos de pesquisa devem ser experimentais: seus objetivos existem mas de forma difusa, permitindo que as coisas vão surgindo a partir de observação bastante atenta, intensa. Mol (2005) chama isso de política ontológica: tal política tira o pesquisador do lugar daquele que sabe e ele passa a se sentar no lugar de experimentador, do que não tem pressa, do que não queima etapas, não está preocupado com as metas que tem que atingir; o pesquisador vai para o lugar daquele que não deixa que os fatos o levem tão rapidamente para uma conclusão. Nessa situação, a proposta de verdade científica está à frente, é uma possibilidade, não há garantia de que vai dar certo. 


\title{
\|
}

Assim, a teoria ator-rede, como ferramenta prática, indica a quarta noção: que é preciso ser experimental; buscar, tentar, observar, e a realidade estudada vai emergindo por meio das mediações e processos que vamos identificando ao seguir os atores do cotidiano, nos processos, nas ações que praticam, naquilo que "fazem-fazer". Tais reflexões nos levaram a compreender uma questão que está bem formulada no estudo intitulado "Reagregando o Social" escrito por Latour(2012). Afinal, o que é social? O que significa a palavra "social" quando associada às expressões "fator social", "contexto social", "psicologia social"? Esse "social" explica alguma coisa? No âmbito da teoria ator rede, não. Social é o que precisa ser explicado. Na prática da pesquisa, - que isso significa? Significa abordar o social mais com perguntas/questões do que com categorias prontas (quarta noção), um pouco às avessas, um pouco no feminino, como Manoel de Barros (2003, p.09) faz ao escrever, por exemplo, o Apanhador de Desperdícios:

\begin{abstract}
Uso a palavra para compor meus silêncios. Não gosto das palavras fatigadas de informar. Dou mais respeito às que vivem de barriga no chão tipo água pedra sapo. Entendo bem o sotaque das águas. Dou respeito às coisas desimportantes e aos seres desimportantes. Prezo insetos mais que aviões. Prezo a velocidade das tartarugas mais que as dos mísseis. Tenho em mim esse atraso de nascença. Eu fui aparelhado para gostar de passarinhos. Tenho abundância de ser feliz por isso.
\end{abstract}

Gostaríamos de sublinhar algo sobre a construção do conhecimento sobre a realidade que defendemos nesse artigo: ter menos certezas, menos hipóteses, antecipar menos os resultados não significa deixar de ser ético ou ser descuidado com a metodologia da pesquisa. Apenas, o que queremos dizer, é que o excesso de conhecimento prévio atrapalha a pesquisa. Se antecipamos tudo o que pode ser visto, tiramos o sabor, inviabilizamos a investigação. Por isso, é saudável para o processo de construção de conhecimento sobre a realidade, não determinar, a priori, como as coisas devem ser. Afinal, esse 


\section{A $\mathrm{\text {REVISTA }}$ APOTHEKE}

lugar determinado a priori é um lugar de oposição entre visões de mundo - justo do que nós aqui queremos escapar. Então, na prática, qual é a estratégia para explicar o social, esse nosso mundo comum e reconhecer os diálogos nas diferenças?

A teoria ator-rede diz "Siga os atores, descreva as associações". E, nós aprendemos que isso é tão simples quanto difícil e poderoso, pois implica considerar o papel dos não humanos, considerar que eles têm agências, provocam associações, produzem associações; isso é muito poderoso: traduz o que Boff (2009) nos explica e define como "crise ecológica" e que permite compreender a Terra como sujeito para além de objeto explorado tal como são os pobres, sujeitosobjetos. A noção de crise ecológica de Boff (Op. cit.) é emblemática da crise do paradigma ocidental de influência platônica e que nos desafia a superar os abismos dualistas de toda ordem: natureza-cultura, corpo-alma, racional-sensível, conceitos-contextos, fatos-valores, ciência-arte. Dentre as noções que queremos compartilhar, essa é mais uma, portanto, que nos ajuda a construir o argumento sobre a existência do que ressoa do saber tradicional/popular no saber científico e vice versa, argumento que fortalece a não-hierarquização entre eles. Como nos propõe Alves (2010) ao discorrer sobre as razões da pesquisa nos/dos/com os cotidianos.

\section{III.1 - Fazer ciência, fazer vida, fazer arte}

Revisitamos o caso de pesquisa com ceramistas fluminenses que reiteram que "a cerâmica fala numa interação silenciosa". Mas, para interpretar e dialogar com o barro, é necessário "estar disponível". A transformação não é somente do barro pelo homem, mas também do homem que aprende a partir desse objeto - quase-sujeito (BRANQUINHO, LACERDA, COSTA, 2013).

Afinal, as ciências e as técnicas são plenas de não humanos imersos em nossa vida comum; do celular, que parece 


\section{X|}

alterar as noções de tempo e espaço; ao satélite que, à distância, mostra algo de nós mesmos. Do dispositivo hospitalar que mantém a vida no limite ao DNA que indica a paternidade de uma criança (e que o faz no lugar da mãe, antes - ser mais autorizado para indicar quem é esse pai...). Trata-se assim de uma ferramenta poderosa por fazer pensar que uma parte da nossa humanidade é feita da inumanidade dos objetos tal e qual acontece nas sociedades que não possuem a ciência como instrumento de leitura do mundo, um pouco na contra mão do que sugeriu Levi-Strauss (1989). Não são os outros - os donos do pensamento selvagem - que se equiparam a nós por terem um tipo de ciência, a ciência do concreto, porque a capacidade de classificar está na base de todo pensamento. Somos nós que, apesar da ciência tentar separar o objeto do sujeito, a natureza da cultura, permanecemos misturando-os.

Considerando que essa interdependência é ontológica, essa noção nos ajuda a pensar um mundo mais democrático. Concordarmos com a noção segundo a qual a possibilidade do fim da guerra no mundo pode estar associada ao fim da guerra de mundos, como a que é travada entre o mundo da Ciência e o mundo dos saberes tradicionais. Quem sabe, não poderemos ir substituindo a noção de conflito pela de controvérsia, bem mais lúdica, construtiva e espontânea?

Temos que reconhecer, portanto, que nós - sociedade cientifica e técnica - tal como as sociedades ditas "primitivas", somos tecidos na heterogeneidade humano-nãohumano e, diante dessa noção de interdependência, refazemos a pergunta: o que é humano? O que conta como humano? E o que isso conta na nossa humanidade? Essas são, sim, perguntas que nos ajudam a pensar a composição de um mundo comum a todos, mais democrático. É diante dessa noção de interdependência que afirmamos que as plantas, que os jardins nos humanizam. 


\section{Hervysta \\ (1) APOTHEKE}

Saramago (2005, p.152-53) traduz a indissociabilidade entre humano e não-humano, brilhantemente, em A Caverna, quando na fala de Cipriano Algor, nos diz:

Ia medir-se com o barro, levantar os pesos e os alteres de um reaprender novo, refazer a mão entorpecida, modelar umas quantas figuras de ensaio que não sejam declaradamente, nem bobos nem palhaços, nem esquimós, nem enfermeiras, nem assírios nem mandarins, figuras de qualquer pessoa, homem ou mulher, jovem ou velha, olhando-as pudesse dizer, Parecem-se comigo. E talvez que uma dessas pessoas, mulher ou homem, velha ou jovem, pelo gosto e talvez a vaidade de levar para casa uma representação tão fiel da imagem que de si própria tem, venha à olaria e pergunte a Cipriano Algor quanto custa aquela figura de além, e Cipriano Algor dirá que essa não está para venda, e a pessoa perguntará o porquê, e ele responderá, Porque sou eu.

Isso significa dizer que, com esses operadores cognitivos, confirmamos o que autores de diferentes matizes teóricos dizem sobre o fato da nossa sociedade científica e técnica não se encaixar na dicotomia natureza-sociedade. Praticamos o duvidar das fronteiras e hierarquias, a revisão da noção de tempo, a observação da realidade bem devagar, degustando-a, seguindo os atores que fazem-fazer, sem categorias prévias, - independentemente se são humanos ou não -; ou seja, redesenhando as fronteiras entre humano e não humano: esses são procedimentos teórico-metodológicos que podem contribuir para desfazer como absolutas outras dicotomias do nosso cotidiano: corpo/alma, natural/sobrenatural, racional/sensivel, fato/contexto, popular/cientifico, sagrado/profano, ocidente/oriente, vida/não vida, ciência/arte... e nos ajudar a substituir conflitos, às vezes corporais, por controvérsias, prazerosas conversas.

No fim de tudo, há um grande aprendizado político: aceitamos o convite transgressor de Manoel de Barros (1996), quando nos diz que "é preciso transver o mundo". O resultado dessa transgressão diz que faz sentido formular a questão: será que humano em nossa sociedade científica e técnica não pode ser o efeito dessa heterogeneidade? Provisório, 


\section{X|}

inconstante, incerto, indeterminado, híbrido. Será que, assumindo esses procedimentos de pesquisa -, não ajudamos a ciência a se reapresentar diferente frente aos outros saberes? Será que isso nos ajuda a construir práticas educativas transformadoras?

A escolha pela postura epistemológica descrita nesse artigo é eminentemente política. Há, para nós, mais uma razão para a teoria ator-rede ser tão poderosa para nos ajudar a defender a desierarquização entre saberes. Está presente uma pegada da pesquisa, trazida nos anos 80, por Mol (2005), por Haraway(2003), que é a questão do cuidado, o modo como se constrói o olhar, pesquisa que se faz pela proximidade, pelo vínculo e não pelo distanciamento, pensando a pesquisa que se faz "com" e não "sobre" o outro... Não é assim tão evidente o que está incluído nesse com. Do que ele é tecido? É preciso hesitar, ir devagar. E, talvez aceitar mais um convite de Manoel de Barros (1996, p.73), quando diz no texto Livro sobre nada: Os outros: o melhor de mim, sou eles!

Esse enfoque antropológico - o que o Outro mostra de mim? - associado à noção de cuidado, ao pesquisar com e não sobre o Outro - é muito característico de um olhar que pretende capturar a complexidade, um olhar grande em generosidade, percepção, sensibilidade e cuidado com aquilo que se estuda. Sabemos que trazer esse tipo de narrativa para o espaço acadêmico também é fato político, já que nossos relatos também são desafios, campo de experimentação. O relato científico também reverbera na rede, também é parceria, também é ator. Afinal, isso que chamamos de mundo são versões, a pesquisa também produz mundos. Assim é que se aproxima da arte. Suscitamos então, pela imagem 3, a indagação: - Ah... o que o sorriso da jovem pesquisadora pode validar? 


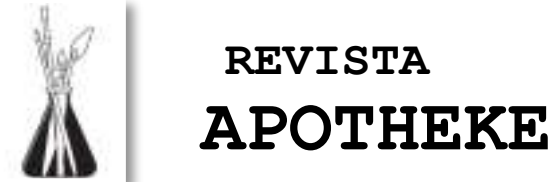

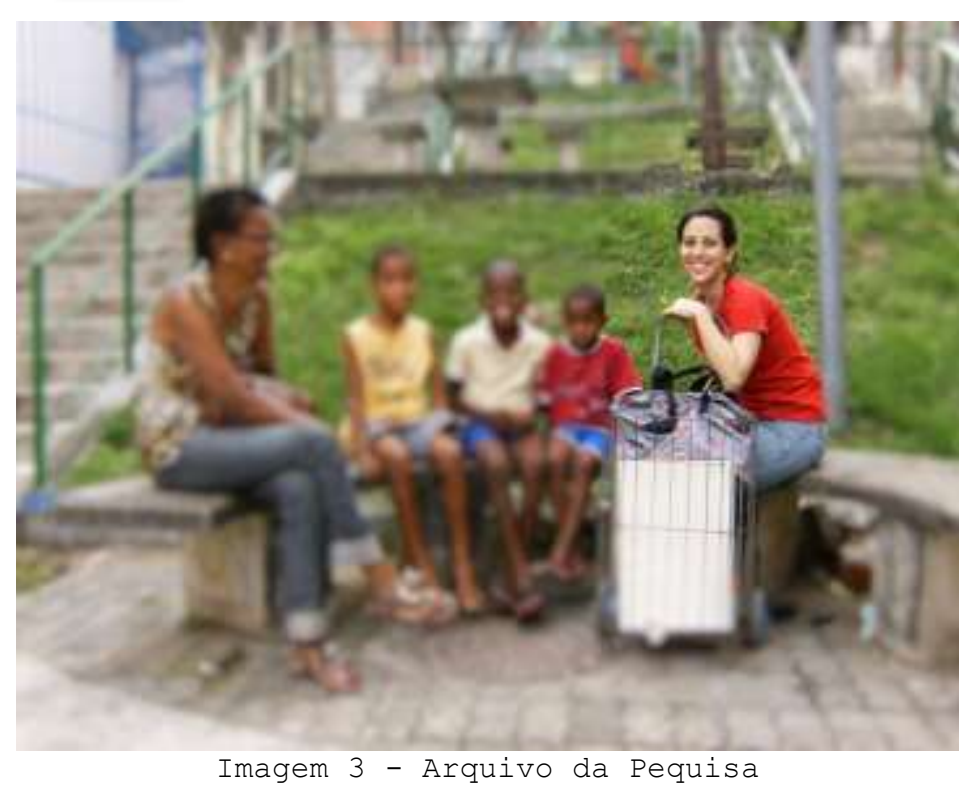

\section{IV - Reflexões finais \\ - troca de saberes e produção de espaços relacionais:}

Em nosso projeto, as atividades se disseminam por nova frente: neste momento estamos iniciando um pequeno "berçário" de plantas medicinais no Centro Social da Candelária, nova

zona a ser dinamizada na Mangueira. Ali nos localizamos na "Praça dos Idosos", em oficinas de argila, crianças e idosos vão interagindo nesta nova plataforma de criação. Esperando seguir com a dispersão desses focos de ação em que ciência e arte se entrelaçam na defesa da vida. Pouco a pouco, lidando com espaços de convivência, aprofundando, expandindo-os. Crianças e idosos interagindo em uma nova frente de ação. Esperando seguir com a dispersão desses focos de ação em que ciência e arte se entrelaçam na defesa da vida. Pouco a pouco, lidando com espaços de compartilhamento. Nesse território onde as formas se equivalem (GROYS, 2008) e se somam em um projeto maior, indeterminado e efêmero - nessa equidade em que não se homogeneízam, mas se colocam em valores contíguos através da relação; ali onde todos podem encontrar o seu modo de pertencimento. 


\section{R| Revrssa \\ (A) APOTHEKE}

Cercados pela violência, seja policial, seja do tráfico, vamos ocupando com a força neutra e fecunda dos canteiros e discutindo ambiente, saúde, beleza. O jardim inaugura um espaço de contemplação de nós mesmos, é uma fresta de vida, onde a vigência da natureza se instala no interior da comunidade. Ali se busca fortalecer, eminentemente, um espaço de convivência, de jogo ou repouso. Um campo de práticas artísticas e científicas integradas para afirmar o estado de liberdade.

Estamos a produzir o Jardim da Tia Neuma como um mundominiatura(CAUQUELIN, 2007); nosso pequeno universo (alma do mundo) que habita este jardim onde, quem sabe, terá lugar para um plano de recomeço de vida, de retomada do existir, uma vida voltada para o nosso próprio bem-estar; um mundo mais que plural, comum. Uma pequenina porção do Paraíso - espaço da Utopia - Utopos - que é para nós esse lugar sem regra, sem dono, sem divisões e sem a "árvore do saber". Temos as conversas sobre o capim radicante, rasteiro, e seus grilos, que aprendemos a respeitar. Temos as batatas doces e as abóboras e todas as forças que nos conseguem conjugar. Recolhemos as sementes do milho que vamos plantar em julho e esperar o ano virar. E, depois, quando o sol estourar no próximo verão, ir colher as narrativas deste processo.

\section{BIBLIOGRAFIA}

ALVES, Nilda. Sobre as razões das pesquisas nos/dos/com os cotidianos. In: Garcia, RL, organizadora. Diálogos cotidianos. Petrópolis/RJ: DP et Alii/FAPERJ; 2010. p.67-82.

ALVES, Daniele. ROCHA, Luisa. Jardins Históricos da Chácara da Hera: Um espaço de relações e experiências. In: $3^{\circ}$ Colóquio Ibero-Americano Paisagem Cultural, Patrimônio e Projeto. Belo Horizonte, 2014. Disponível em:

<http://www. forumpatrimonio.com.br/paisagem2014/artigos/pdf/18 4.pdf>. Acesso em: 10 out. 2015.

AUGÉ, Marc. O Antropólogo e o mundo global. Petrópolis, Editora Vozes, 2014. 


\section{A.}

BARROS, M. Memórias Inventadas: a Infância. São Paulo: Planeta, 2003.

BARROS, M. Livro sobre nada. Rio de Janeiro: Record, 1996. BERJMAN, Sonia. De los jardines históricos a los paisajes culturales: la labor de ICOMOS. In: SIMPÓSIO ARQUEOLOGIA NA PAISAGEM: UM OLHAR SOBRE OS JARDINS HISTÓRICOS, 2, 2011, Rio de Janeiro. Caderno de Resumos... Rio de Janeiro: EBA/UFRJ, 2011. Disponível em:

<http://www.eba.ufrj.br/historiadopaisagismo/images/arquivos/a rqueologia_na_paisagem_2011.pdf>. Acesso em: 12 nov. 2013. BESSE, Jean-Marc. Ver a Terra. São Paulo, Perspectiva, 2014. BRANQUINHO, F.T.B. O poder das ervas nos saberes popular e científico. Rio de Janeiro: MAUAD X; 2007.

BRANQUINHO, F.T.B., LACERDA, F.K.D., COSTA, R.P.N. Fazendo pesquisas sobre ceramistas fluminenses e pensando a educação para a democracia do ponto de vista de teoria ator-rede. In: Anais do VII Seminário Internacional - As Redes Educativas e as Tecnologias: transformações e subversões na atualidade, Rio de Janeiro, 2013.

BOFF, Leonardo. Opção Terra: a solução para Terra não cai do céu. Rio de Janeiro: Record, 2009.

CALLON, M. Agir dans um monde incertain, recherche confinee et recherche de plein air; 2003.

CAPRA, F. A Botânica de Leonardo da Vinci: um ensaio sobre as ciências das qualidades. São Paulo: Cultrix, 2011. CAUQUELIN, Anne. A Invenção da Paisagem. São Paulo, Martins Fontes, 2007 .

CONDURU, R. Nego Esculturas da terra. Ministério da Cultura. Fundação Nacional de Arte. Centro Nacional de Folclore e Cultura Popular. 1998.

DANOWSKY, Débora e VIVEIROS DE CASTRO, Eduardo. Há um mundo por vir? Ensaio sobre os medos e os fins. Florianópolis, Instituto Socioambiental, 2015.

DERRIDA, Jacques. Posições. Belo Horizonte, 2001. DIDI-HUBERMAN, Georges. Sobrevivência dos Vaga-lumes. Belo Horizonte, Ed. UFMG, 2014.

DOURADO, Guilherme Mazza. A Belle Époque dos Jardins. São Paulo, SENAC, 2011.

CURY, Isabelle (Org.). Cartas Patrimoniais. Brasília: IPHAN, 2000 .

FRADE, Isabela. Arte Ambiental: Formas Relacionais na Modelagem dos Lugares. Revista Palíndromo, v. 4, n. 8, 2012. Disponível em: 


\section{《I}

<http://www.revistas.udesc.br/index.php/palindromo/article/vie w/3452>. Acesso em: 30 nov. 2015.

- O CÍRCUlo - Ativando a produção plástica

feminina na Via UERJ/Mangueira. In ANAIS IXX ANPAP. Cachoeira, UFCA, 2010.

GROYS, Boris. Art Power. Cambridge, The MIT Press, 2008.

HARAWAY, D.J. The companion species manifesto: dogs, people and significant otherness. Chicago: III Bristol Paradigm, University Presses Marketing; 2003.

HARLAN, Volker. A Planta como arquétipo da Teoria da Plasticidade. in Beuys, Joseph. A Revolução somos nós. São Paulo, SESC, 2010.

LATOUR, B. Reagregando o social: uma contribuição à teoria ator-rede. Salvador: Edufba; 2012.

LATOUR, B. Jamais fomos modernos: ensaio de antropologia

simétrica. Rio de Janeiro: Editora 34; 1994.

LEVI-STRAUSS, C. O pensamento selvagem. Campinas, SP: Papirus, 1989.

MATURANA, Humberto e VERDEN-ZOLLER, Gerda. Amar e Brincar Fundamentos esquecidos do humano. São Paulo: Palas Atenas, 2009 .

MOL, A. The body multiple: ontology in medical practice. Duham and London: Duke University Press; 2005.

NOGUEIRA, M.A.L. Almanaque: toda oficina da vida. Recife:

Fundação de Cultura da Cidade do Recife; 2008.

PANZINI, Franco. Projetar a natureza. São Paulo, SENAC, 2013.

SARAMAGO, J. A caverna. São Paulo: Companhia das Letras; 2000.

STENGERS, Isabelle. Une autre science est possible! Empêcheurs de penser en rond/La Découverte, 2013.

MOL, A. The body multiple: ontology in medical practice. Duham andLondon: Duke University Press; 2005.

NOGUEIRA, M.A.L. Almanaque: toda oficina da vida. Recife: Fundação deCultura da Cidade do Recife; 2008.

PANZINI, Franco. Projetar a natureza. São Paulo, SENAC, 2013. SARAMAgo, J. A caverna. São Paulo: Companhia das Letras; 2000.

Fátima Branquinho - Graduada em Licenciatura em Biologia/Uerj, com Mestrado em Educação/IESAE-FGV e Doutorado em Ciências Sociais/Unicamp. É Profa Associada da Faculdade de Educação e do Programa de Pós Graduação em Meio Ambiente da Uerj. Coordena projetos de extensão e de pesquisa com apoio FAPERJ/Cientista do Nosso Estado. 


\section{REVISTA}

APOTHEKE

Fátima Kzam - Graduada em Licenciatura em Química e Engenharia Química, com Mestrado em Tecnologia de Processos Bioquímicos e Doutorado em Ciências do Meio Ambiente. É Profa Adjunta do Instituto de Química da UERJ atuando nos seguintes temas: educação em ciências, educação ambiental, formação de professores. Pós-Doutoranda do PROPED/UERJ.

Isabela Frade - artista e educadora, professora associada do Instituto de Artes da UERJ. Líder do GP- CNPQ Observatório de Comunicação Estética e coordenadora do projeto Terra Doce; tem pesquisado arte pública, espaços relacionais e formas de saberes comunais. É PROCIENTISTA FAPERJ.

Daniele Alves - arte educadora e museóloga. Doutoranda em artes do PPGARTES/UERJ, membro do Grupo de Pesquisa Observatório de Comunicação Estética. Bolsista FAPERJ.

[1] Tia Neuma, Neuma Gonçalves da Silva, mesmo depois de sua morte, em 2000, com a idade de 78 anos, é figura de referência como matriarca mangueirense e ainda muito querida, pois fez muito pela comunidade: abriu duas creches e uma escola ainda em funcionamento. O chamado de "Tia" substitui o "Dona" que muitas senhoras recebem entre eles pela sua atitude carinhosa e protetora. Além de pessoa bondosa e prestativa, era festeira: foi fundadora da ala das baianas na escola de samba. 